Rev. Hist., N²8, vol. 1, Enero-Junio 2021: 423-448

ISSN 0717-8832

https://doi.org/10.29393/RH28-16OPVV10016

\title{
Oportunidades perdidas. Alzamientos federalistas en Chile (1827 y 1828)
}

Lost Opportunities. Federalist Uprisings in Chile (1827-1828)

Valentina Verbal Stockmeyer ${ }^{*}$

\section{RESUMEN}

Este artículo estudia dos importantes alzamientos castrenses que la historiografía suele asociar al proyecto político federalista: el de Enrique Campino (1827) y el de Pedro Urriola (1828). Para ello, este trabajo se interroga sobre el carácter federalista de estas sublevaciones, así como sobre las razones de su fracaso. Además, se sostiene que, contrariamente a lo que historiografía ha solido decir al respecto, la causa del fracaso del proyecto federalista en Chile puede encontrarse no sólo en las dificultades que supuso la aplicación de ese proyecto, sino también en la indecisión política de aceptar la conquista del gobierno por la vía armada.

Palabras clave: Alzamientos federalistas, militarismo, Enrique Campino, Pedro Urriola, José Miguel Infante.

\section{ABSTRACT}

This article studies two important military uprisings that historiography usually associates with the federalist political project: the uprising of Enrique Campino (1827) and of Pedro Urriola (1828). To do this, this work questions the federalist nature of these uprisings, as well as the reasons for their failure. Furthermore, the author maintains that, contrary to the usual stand of historiography on the matter, the cause of the failure of the federalist project in Chile can be attributed not only to the difficulties associated with the application of that project, but also to the political indecision on accepting the conquest of the government by armed means.

Keywords: Federalist uprisings, militarism, Enrique Campino, Pedro Urriola, José Miguel Infante.

Enviado: diciembre 2020

Aceptado: mayo 2021

\footnotetext{
* Magíster en Historia por la Universidad de Chile. Estudiante de doctorado en Atlantic History en Florida International University (Miami). ORCID ID: https://orcid.org/0000-0002-0650-1565. Correo electrónico: vverb001@fiu.edu.
} 


\section{Introducción}

En La fronda aristocrática, Alberto Edwards no duda en tipificar el periodo 1823-1830 como de anarquía. En esta obra, titula el capítulo VI como interregno anárquico, describiéndolo como sigue: "En Chile tuvimos un remedo de aquel orden de cosas netamente sudamericano, durante los siete años que transcurrieron entre la caída de O’Higgins y la revolución de 1829 . Se ha dado a aquella época el nombre convencional de 'era de los pipiolos'; en realidad fue solo el tiempo de nuestros gobiernos 'sin forma'" ${ }^{1}$. Por su parte, Julio Heise niega tajantemente la existencia de anarquía para dichos años, adoptando la tipificación de aprendizaje o de ensayos constitucionales". Dice Heise: "Para los historiadores conservadores [como Edwards], el militarismo, las dictaduras, el desorden y la miseria moral y material habrían sido las características de este período" ${ }^{3}$. Sin embargo, señala que lo que realmente habría existido en Chile es un proceso natural de descolonización, que daría cuenta de un "cuerpo social convulsionado por frecuentes oscilaciones entre el estilo tradicional de la Madre Patria y las fuerzas renovadoras que lo impulsan a la renovación" ${ }^{4}$. Además, y no obstante su negativa de calificar el periodo referido de anarquía, y de negarse de plano a reconocer la existencia de militarismo ${ }^{5}$, Heise reconoce una única "patología" para el lapso de tiempo aquí referido: la de "constitucionalismo utópico", que aplica especialmente para el denominado ensayo federal de 1826, proyecto político liderado por José Miguel Infante. ${ }^{6}$

¿Qué entiende Heise por constitucionalismo utópico? ¿Por qué aplica esta categoría al ensayo federal de 1826? Para Heise, dicho fenómeno se da cuando predominan "los ideólogos con muchas y muy nobles ilusiones, pero con total olvido de la compleja y contradictoria realidad"7. Será con el ensayo federal cuando el constitucionalismo utópico se llevará al extremo: "Al ensayar el federalismo, la clase dominante chilena agudizó la oposición entre norma jurídica y norma vital". Y añade: "Nadie se detuvo a examinar si la realidad

\footnotetext{
${ }^{1}$ Edwards, Alberto. 1997. La fronda aristocrática en Chile, Santiago, Editorial Universitaria, p. 57. Esta obra fue originalmente publicada en 1928.

2 Una visión intermedia entre Edwards y Heise puede leerse en Armando Cartes, para quien, durante esos años: "El país osciló, en efecto, entre la instalación de un Estado multipolar (¿confederal?), multicultural y liberalmente más avanzado, versus el Estado forzadamente homogéneo y centralizado que finalmente se instauró". Cartes M., Armando. 2028. "De época maldita a epopeya liberal. Una revisión historiográfica a la anarquía chilena (1823-1830)", Illes $\mathrm{i}$ Imperis, $\mathrm{N}^{\circ} 20$, Barcelona, p. 20.

3 Heise, Julio. 1978. Años de formación y aprendizaje políticos 1810-1833, Santiago, Editorial Universitaria, pp. 1112.

4 Ídem.

5 "La etapa de organización del Estado no conoció en Chile el militarismo. Los soldados que actúan en esta época O’Higgins y Freire- fueron exaltados por elementos civiles, como símbolos de gloria y orgullo nacional y ellos se inclinaron ante el poder civil y ante la juridicidad". Ibíd., p. 128.

${ }^{6}$ La expresión "constitucionalismo utópico" también la utiliza para referirse a las ideas que Juan Egaña vertió en la Constitución de 1823. Ibíd., p. 161.

7 Ibíd., p. 150.
} 
norteamericana coincidía o no con la de los pueblos hispanoamericanos. El ensayo condujo, precisamente, a todo lo contrario de lo que pretendía imitar; a todo lo contrario de lo que realizaron los patriotas norteamericanos" 8 .

Ahora bien, ¿̇en qué consistió dicho ensayo? En términos formales, en la dictación de diversas disposiciones legales que, sin alcanzar nunca el grado de constitución, apuntaba a pavimentar el camino hacia un proyecto federal definitivo para el país. Veamos aquí algunos hitos claves en este proceso. El 19 de enero de 1826, el general Ramón Freire logró independizar el archipiélago de Chiloé del imperio español y anexarlo al territorio de Chile. De esta manera, se completó la Independencia chilena en términos militares. Unos pocos días después (el 31 de enero), el Consejo Directorial, liderado por Infante, y que gobernaba en reemplazo de Freire, dictó un decreto que dividió al país en ocho provincias: Coquimbo, Aconcagua, Santiago, Colchagua, Maule, Concepción, Valdivia y Chiloé. ${ }^{9}$ El 8 de julio, el Congreso aceptó la renuncia de Freire. Su sucesor, Manuel Blanco Encalada, vino así a ser el primer Presidente de la República, ya que un decreto había dispuesto esta nueva denominación para dicha magistratura. Además, se estableció el cargo de vicepresidente como sustituto del presidente "en los casos de enfermedad, ausencia y otros". ${ }^{10}$ Para este cargo, el parlamento eligió a Agustín de Eyzaguirre. El 11 de julio el Congreso dictó una ley que dispuso que la "república de Chile se constituye por el sistema federal, cuya Constitución se presentará a los pueblos para su aceptación"11. El 17 de julio, una segunda ley sobre elección de los cabildos, gobernadores e intendentes ${ }^{12}$. Y el 26 de ese mes una tercera ley sobre elección de párrocos. ${ }^{13}$

En el marco del contexto referido en el párrafo anterior, el presente artículo tiene por objeto tratar dos insubordinaciones castrenses, que la historiografía suele asociar al grupo federalista. La primera de ellas aconteció en la ciudad de Santiago, en 1827, y la otra tuvo lugar al año siguiente, en la ciudad de San Fernando. Sin embargo, el segundo caso no se reducirá a dicha ciudad, puesto que las fuerzas sublevadas Ilegaron hasta las puertas del palacio de gobierno en la capital del país.

Son tres las grandes preguntas que este trabajo buscará responder: a) ¿tuvieron, y hasta qué punto, dichos alzamientos un carácter federalista?; b) si en alguno u otro grado lo tuvieron, ¿puede la caída del proyecto federal reducirse meramente a su carácter "utópico", sin considerar el fracaso concreto de las sublevaciones estudiadas en el presente trabajo?; y c) ¿por

\footnotetext{
8 lbíd., p. 176.

${ }^{9}$ Barros Arara, Diego. 2005. Historia general de Chile, vol. XIV, Santiago, Editorial Universitaria - Centro de Estudios Diego Barros Arana, p. 419. Esta obra fue originalmente publicada en 1897.

${ }^{10}$ Citado por Ibíd., p. 29.

11 Letelier, Valentín. 1901. Sesiones de los Cuerpos Legislativos, vol. XII, Santiago, Imprenta Cervantes, p. 96. En adelante esta fuente, se citará sólo por el título, volumen y página.

12 Ibíd., p. 159.

13 Ibíd., p. 231.
} 
qué no llegaron esos alzamientos a "buen término", en el sentido de derrocar a los gobiernos a los que se enfrentaron?

La segunda pregunta es importante porque, como otros autores han argumentado ${ }^{14}$, el triunfo pelucón de 1829 no se explica solamente por la debilidad intrínseca de la Constitución de 1828, sino también por el hecho de que los conservadores, liderados por José Joaquín Prieto y Diego Portales, llevaron a cabo una sublevación castrense, que luego devino en guerra civil, y que finalmente concluyó con la victoria de los alzados en la batalla de Lircay del 17 de abril de 1830. Lo mismo, pero al revés -es decir, en términos de su fracaso- cabe indicar para los alzamientos federalistas estudiados en el presente artículo.

La tercera pregunta se vincula más directamente con la cuestión del militarismo. En concreto, pese a las innegables dificultades en la aplicación del régimen federal en el país, este trabajo sostendrá la tesis según la cual la caída de este proyecto se debió, en no poca medida, al fracaso de las acciones de insubordinación castrense referidas en este trabajo, especialmente la de 1828. Se trata de un punto de vista "heterodoxo", precisamente por el hecho de que buena parte de la historiografía sobre Chile ha negado -o al menos minimizado - la existencia de militarismo para la post Independencia. Por ejemplo, y además de Heise -que niega de plano la existencia de militarismo para el periodo $1823-1830^{15}$, Sergio Vergara Quiroz habla de la existencia de un "militarismo latente", "como un peligro eventual, expresándose en conspiraciones y motines" ${ }^{16}$. Sin embargo, y como más abajo se verá, los alzamientos federalistas de 1827 y 1828 no pueden calificarse de latentes, sino de abiertos y activos.

Por otro lado, Gabriel Salazar resume el período 1823-1830 en la lucha entre dos grandes fuerzas: "democracia de los pueblos", apoyada por un "militarismo ciudadano", versus "aristocratismo centralista", ayudado, a su vez, por un "militarismo cesarista u oligárquico". La primera se vincula con los procesos de deliberación política que se dan en el marco de las asambleas locales o municipales, por ejemplo, ayuntamientos o cabildos ${ }^{17}$. Por militarismo ciudadano, Salazar hace referencia al uso de la fuerza armada para defender el derecho de los pueblos (de las asambleas locales) a deliberar en torno a la construcción e instalación del Estado. Este militarismo apuntaría a defender "la soberanía viva de los pueblos" en contra de "la soberanía abstracta de la 'nación"” ${ }^{18}$. Este militarismo ciudadano habría sido liderado, desde

\footnotetext{
14 Por ejemplo, y recientemente, San Francisco, Alejandro. 2020. "El Ejército y la definición de sus principios constitucionales. Obediencia y no deliberación política en Chile. 1829-1830", Historia Caribe, vol. 15, № 36, Barranquilla, pp. 235-277.

${ }^{15}$ Heise, Años de formación, p. 4.

16 Vergara, Sergio. 1993. Historia social del Ejército de Chile, volumen I, Santiago, Departamento Técnico de Investigación - Universidad de Chile, pp. 99-100.

17 Salazar, Gabriel. 2011 [2006]. Construcción de Estado en Chile (1800-1837). Democracia de los "pueblos". Militarismo ciudadano. Golpismo oligárquico, Santiago, Editorial Sudamericana, p. 54.

18 Ibíd., p. 171.
} 
enero de 1823, por Ramón Freire, en contra del militarismo cesarista (o autocrático) del Director Supremo, Bernardo O'Higgins.

Por su parte, Verónica Valdivia Ortiz de Zarate sostiene que la importancia de los militares en la época radica, principalmente, en la tarea de disciplinamiento (o de lealtad forzada) de los sectores populares en favor del Estado que se estaba construyendo ${ }^{19}$. Además, en la misma línea de Salazar, destaca la existencia de un "liberalismo militar", partidario del "principio de representación (aunque censitario), derechos provinciales y libertades públicas", simbolizados en la figura de Freire ${ }^{20}$. Sin embargo, Valdivia no se aproxima al militarismo como categoría autónoma de análisis, sino que centra el papel de los militares en la construcción del Estado más o menos cerca de los sectores populares. En otras palabras, y al igual que Salazar, no logra detectar el militarismo como un fenómeno estructural del período, es decir, transversal a los bandos políticos que en él actuaban.

Una razón que puede ayudar a explicar el hecho de que la mayoría de la historiografía le asigne poca importancia al militarismo como factor clave en el periodo de formación del Estado se refiere a la reducción del concepto a la subordinación de los civiles al "estamento militar". Sin embargo, dicho concepto se refiere más bien al hecho de abandonar las tareas estrictamente profesionales, referidas a la defensa nacional. Esto quiere decir que, al inmiscuirse en la vida política, los militares no actúan necesariamente de manera orgánica o corporativa en contra de los civiles, sino junto a ellos, a favor o en contra de tal o cual tendencia partidista. En pocas palabras, el militarismo de la década de 1820 supuso una coparticipación civil-militar. En este sentido, Samuel E. Finer afirma que, normalmente, se piensa que "la forma característica de la intervención militar es el derrocamiento violento de un gobierno, y su 'nivel' corriente, el establecimiento de dominio militar liso y llano. Sin embargo, la gravitación de los militares sobre el gobierno suele desarrollarse entre bastidores"21.

Pero concretamente, ¿qué es el militarismo? Gianfranco Pasquino constata que, históricamente, el término surgió en Francia, bajo el Segundo Imperio, a partir del golpe de estado de Luis Bonaparte ( 2 de diciembre de 1851); y que luego "se difundió rápidamente en Inglaterra y Alemania para indicar la predominancia de los militares sobre los civiles"22. Hermann Oehling distingue la existencia de un militarismo social, que consiste en militarizar "la mayor parte de las esferas de la vida social, impregnando de aire militar la conducta de los

\footnotetext{
19 Pinto, Julio y Valdivia, Verónica. 2009. ¿Chilenos todos? La construcción social de la nación (1810-1840), Santiago: LOM Ediciones, p. 134. Valga aclarar que Verónica Valdivia es la autora de los capítulos II, III y VI, directamente asociados a los militares.

20 Ibídem, p. 153.

${ }^{21}$ Finer, Samuel. 1969. Los militares en la política mundial, Buenos Aires, Editorial Sudamericana, p. 15.

22 Pasquino, Gianfranco. 1991. "Militarismo", en Norberto Bobbio, Nicola Matteucci y Gianfranco Pasquino (directores), Diccionario de Política, Madrid, Alianza Editorial, p. 963.
} 
individuos", de un militarismo político, que supone "la preponderancia de lo militar en algún aspecto fundamental de la vida del país, de modo que sea impropio" 23 .

El federalismo, por su parte, puede ser entendido como la doctrina política que propicia la construcción de un Estado federal, el que a su vez, se relaciona con la llamada "división vertical del poder público" 24 , ya que "propicia dos niveles de gobierno distintos, pero sumamente vinculados por su Constitución federal" 25 . Jorge Carpizo afirma: "En principio un Estado federal es similar a uno central (o unitario): la unidad del Estado es la Constitución, pero la estructura de esa ley fundamental es diferente: en el sistema federal la norma suprema crea dos órdenes subordinados a ella, pero que entre sí están coordinados" ${ }^{26}$. Estos órdenes son el federal y las entidades federativas (estados o provincias federales). Un elemento clave del sistema federal es que las "entidades federales gozan de autonomía y se otorgan su propia ley fundamental para su régimen interno" ${ }^{27}$. Se trata de un elemento esencial desde el punto de vista de la autonomía política de estas entidades. A este sistema aspiraba en Chile el bando federalista, liderado por Infante, pero sin lograr instaurarlo en plenitud.

Este trabajo se ordenará del siguiente modo. En la siguiente sección se tratará la cuestión de las dificultades de la aplicación del federalismo en Chile, a partir del caso de la provincia de Aconcagua. Posteriormente, se abordará el alzamiento liderado por Enrique Campino en 1827. Después de esto, se hará lo propio con el alzamiento de Pedro Urriola en 1828. Finalmente, se cerrará el trabajo con una conclusión orientada a responder de manera sistemática a las preguntas de esta investigación, referidas más arriba.

\section{Dificultades en la aplicación del sistema federal: el caso de Aconcagua}

Como se dijo anteriormente, el sistema federal nunca llegó a concretarse a través de una constitución, sino solo a través de un conjunto de leyes dictadas a mediados de 1826 . Con relación a las leyes electorales, Diego Barros Arana señala que "la repetición de elecciones había creado la discordia entre los pueblos, excitando [...] las ambiciones personales y las rivalidades lugareñas. [...] llegando por fin al desprestigio práctico de este régimen" ${ }^{28}$.

\footnotetext{
${ }^{23}$ Oehling, Hermann. 1977. La función política del Ejército. Santiago: Estado Mayor General del Ejército de Chile, p. 371.

${ }^{24}$ Abdó, Jorge. 2002. "Sistemas de distribución de atribuciones en los estados federales", en José María Serna de la Gaza (coordinador), Federalismo y regionalismo. Memoria del VII Congreso Iberoamericano de Derecho Constitucional, México D.F., Instituto de Investigaciones Jurídicas - Universidad Nacional Autónoma de México, p. 3.

25 Ibídem, p. 4.

26 Carpizo, Jorge. 1973. Federalismo en Latinoamérica. México D.F., Instituto de Investigaciones Jurídicas Universidad Nacional Autónoma de México, p. 15.

27 Ibídem, p. 16.

${ }^{28}$ Barros Arana, Historia general de Chile, vol. XV, p. 79.
} 
Bajo este contexto, comenzó a tornarse crítica una lucha de poder entre el intendente de la provincia de Aconcagua, Francisco Calderón, y el gobernador local de San Felipe, Francisco Mascayano. En las elecciones del 6 de octubre de 1826, Mascayano utilizó toda su influencia política y social para hacer elegir a Pedro Antonio Ramírez como su sucesor. Dado que aparentemente se había cometido fraude, el gobierno central ordenó suspender el proceso que se vivía hasta la constitución de la asamblea provincial, entidad que debía resolver en definitiva el problema ${ }^{29}$. Sin embargo, después de recibir amenazas de parte de las milicias locales y sin que se haya podido constituir la asamblea provincial, Calderón optó por dirigirse a Santiago, "casi en son de fuga, pero acompañado de un cuerpo de milicias, a dar cuenta de aquellos extraordinarios sucesos" ${ }^{\prime 30}$, con el objetivo de reprimir la insurrección. Este incidente llegó a conocimiento del Congreso el 12 de octubre por vía del vicepresidente, Agustín de Eyzaguirre:

“Aunque el vicepresidente de la república se había propuesto no distraer la alta atención del congreso, ni interrumpir sus augustas funciones, haciéndole oír las muchas quejas que frecuentemente se reciben de los pueblos, reclamando la nulidad de algunas elecciones populares, hoy no puede menos que elevar a su consideración la adjunta exposición del intendente de Aconcagua, con el reclamo de los vecinos de las parroquias de San Felipe y Putaendo, contra la que se ha practicado en aquella capital. En ella, según se manifiesta, han sido holladas las más respetables garantías del ciudadano; se ha faltado esencialmente a las prevenciones de la ley de elecciones; se han suspendido arbitrariamente de sus destinos, contra la terminante prohibición de la misma ley, a dos de los jueces territoriales de aquel distrito en el periodo mismo de la elección, y últimamente se ha hecho intervenir la fuerza armada en el acto más libre del pueblo, y acaso el más interesante que pueda presentársele, como que de él va a depender su tranquilidad y bienestar" ${ }^{\prime \prime}$.

Frente a la carencia de una solución definitiva, Eyzaguirre tomó la decisión de "comisionar al coronel don Francisco Elizalde para que pasase inmediatamente a la ciudad de San Felipe, a reclamar por última vez el orden y la obediencia a la suprema autoridad". ${ }^{32}$ El vicepresidente consideraba a la ciudad de San Felipe, bajo el liderazgo de Mascayano y Ramírez, como "amotinadas" en contra del gobierno central ${ }^{33}$. De ahí que la misión de Elizalde consistía, básicamente, en reponer a Mascayano en la gobernación local y disolver las milicias armadas. Después de haber logrado ambos objetivos, Elizalde pudo hacerse reconocer como intendente interino de la Provincia (29 de octubre). Todo parecía marchar sin problemas. Sin embargo, el

\footnotetext{
29 lbídem, p. 82.

30 Ídem.

${ }^{31}$ Sesiones de los Cuerpos Legislativos, vol. XIII, p. 167.

32 Ibídem, pp. 222 y 223.

33 Ibídem, p. 223.
} 
conflicto se reavivó con ocasión de la repetición de las elecciones, ya que la decisión del gobierno de exigirle a Mascayano que saliese del departamento durante el curso del proceso electoral, produjo una profunda molestia en un sector de sus seguidores.

¿Qué sucedió? Bajo la influencia de Mascayano, el 20 de noviembre, un escuadrón de milicias de caballería, encabezado por el sargento Manuel Silva, se tomó el cuartel de cívicos y rodeó la casa de Elizalde. Mascayano justificó estos acontecimientos en la existencia de un descontento popular, agregando que él quería obedecer las órdenes emanadas desde el gobierno central. Pero que "apenas este pueblo lo ha entendido, cuando todos, agolpándose, me protestan que si salgo me siguen; y temiendo que esto parezca una asonada, los he contenido y suspendido mi salida hasta tanto que la soberanía nacional [el congreso] resuelva lo que deba hacerse" ${ }^{34}$. Finalmente, estos incidentes se resolvieron por la vía de la negociación: se acordó reconocer a Elizalde como intendente interino y la convocatoria inmediata a la asamblea provincial. Además, Mascayano retomó su cargo de jefe local en San Felipe. ${ }^{35}$

Si bien el caso referido en esta sección corresponde a una insubordinación de cívicos y no de militares de línea, da cuenta también del militarismo de la época, en este caso de un militarismo social, en los términos de Oehling. Además, da cuenta de la validación de la violencia política como método de resolución de conflictos. Como esta aurora ha señalado antes, en la década de 1820: "Tanto pipiolos como pelucones, no dudaron en utilizar todas las formas de lucha, incluyendo la violencia física, para alcanzar la hegemonía política que perseguían y creían necesitar" ${ }^{36}$. Esta circunstancia no se opone al hecho de que, no pocas veces, los civiles retrocedían y pactaban con sus adversarios cuando la posibilidad del triunfo se veía lejana, o cuando experimentaban una suerte de "cargo de conciencia" por la sangre que habían derramado. Por esta razón, el fracaso del proyecto federal en Chile no cabe reducirlo a las dificultades de su aplicación a partir de un supuesto carácter utópico.

\section{El alzamiento de Enrique Campino de 24 de enero de 1827}

Desde el punto de vista de la estabilidad política, el alzamiento de Campino se sitúa en una época de gobiernos efímeros. En medio de la sublevación o'higginista de Chiloé, el 7 de julio de 1826, Freire había renunciado a su cargo de director supremo. Su sucesor, Manuel Blanco Encalada, no duró mucho tiempo. Después de graves desavenencias con el congreso, sobre todo relativas a la manera de enfrentar la crisis fiscal, el 7 de septiembre renunció también, siendo reemplazado por Agustín de Eyzaguirre, quien ejercía el cargo de vicepresidente. Las

\footnotetext{
${ }^{34}$ Ibídem, p. 285.

${ }^{35}$ Barros Arana, Historia general de Chile, vol. XV, p. 83.

${ }^{36}$ Verbal, Valentina. 2020. "De hermana mayor a madre protectora. Santiago frente a las provincias (1810-1860)", en Armando Cartes (editor), Región y Nación. La construcción provincial de Chile. Siglo XIX, Santiago: Editorial Universitaria, p. 204.
} 
siguientes palabras del renunciado presidente ayudan a situarse en el ambiente que se vivía en la segunda mitad de 1826:

“Contaba asimismo con que el congreso, que palpaba lo crítico de las circunstancias y los apuros del erario, facilitase con una eficaz cooperación, y en perfecta armonía con el poder ejecutivo, todos aquellos recursos indispensables para poder atender a la urgentísimas y diarias necesidades que por todas partes se sienten, y que no han cesado de afligir al gobierno desde el momento de su instalación" ${ }^{37}$.

En palabras simples, la dimisión de Blanco Encalada puede explicarse en el escaso apoyo que había recibido de parte del parlamento. Según Melchor de Concha y Toro: "La renuncia del general Blanco fue, a no dudarlo, bastante precipitada. Si él hubiese esperado, las dificultades de la situación habrían caído con todo su peso sobre el congreso" ${ }^{38}$. Eyzaguirre, a la sazón con sesenta años de edad, tampoco gobernó sin dificultades. El pago del empréstito inglés de un millón de libras esterlinas, concedido en 1822, se estaba tornando imposible. La casa Portales, Cea y compañía, que tenía a su cargo el estanco del tabaco y otros productos bajo la condición de servir esta deuda, no estaba cumpliendo. En Londres se encontraba Mariano Egaña como ministro plenipotenciario, quien el año anterior se había visto obligado a conseguir un préstamo con la casa Barclay, Herring, Richardson y Compañía ${ }^{39}$. Bajo un contexto personal de suma tensión, le escribía a su padre con fecha 25 de septiembre de 1825:

"Los execrables, los malvados, los pérfidos Cea y Portales viven tranquilos. Mas ¿digo viven tranquilos? Se pasean, se ríen en sus tertulias y brindan a la salud del gobierno, a quien tanto conocen; tienen derecho para ser considerados con el miramiento que en Chile se dispensa a los malos, con preferencia a los buenos; y por último, serán tal vez premiados, dándoles un nuevo ramo de monopolio" 40 .

El 21 de septiembre de 1826 el congreso acordó el traspaso de la administración del estanco al Estado. El día anterior, los tres batallones de infantería que guarnecían la ciudad de Santiago se habían amotinado, pidiendo que en un plazo máximo de cuatro días se les cancelasen los sueldos atrasados. Un mes más tarde, la guardia de palacio, integrada por alrededor de cien soldados, hizo lo mismo ${ }^{41}$. Y aunque ninguno de estos motines afectó directamente a los gobiernos existentes, se convirtieron en terreno fértil para acrecentar las diferencias que se

\footnotetext{
${ }^{37}$ Sesiones de los Cuerpos Legislativos, vol. XIII, p. 44.

38 Melchor de Concha y Toro. 1862. Chile durante los años de 1824 a 1828. Memoria histórica leída en la sesión solemne de la Universidad de Chile el 12 de octubre de 1862, Santiago, Imprenta Nacional, p. 112.

${ }^{39}$ Barros Arana, Historia general de Chile, vol. XV, p. 57.

40 Documento transcrito por Domingo Amunategui Solar. 1939. Pipiolos y Pelucones, Santiago, Imprenta y Litografía Universo, p. 75.

${ }^{41}$ Barros Arana, Historia general de Chile, vol. XV, p. 77.
} 
daban en el seno de las elites civiles. El 19 de enero de 1827 se presentó el proyecto de Constitución federal. Pero las dificultades en la aplicación de las leyes de este carácter produjeron una profunda desilusión en un sector del parlamento. Diego José Benavente llegó a preguntar "si era o no revocable el acuerdo que constituyó la república por el sistema federal” ${ }^{42}$.

Ahora bien, y entrando al acontecimiento mismo que es materia de esta sección, el alzamiento del coronel Enrique Campino tiene la particularidad de proceder de una persona que, siendo militar (aunque sin mando de tropa), ejercía al mismo tiempo la función de parlamentario. Se trataba de una época en la cual no existía una separación tajante entre la función parlamentaria y la militar, así como entre la parlamentaria y la eclesiástica. De hecho, la convocatoria al congreso de 1826, realizada por Freire el 15 de marzo de ese año, estableció que podían ser candidatos los eclesiásticos seculares y los militares que posean el grado de alférez, inclusive, para arriba. ${ }^{43}$

Nacido en 1794, Campino se incorporó al ejército en 1810. El 1 de abril de 1811 le tocó sofocar el alzamiento realista de Tomás de Figueroa. Más tarde, formó parte del Ejército de los Andes y combatió en las batallas de Chacabuco y Maipú en 1817 y 1818, respectivamente. En 1820 participó en la expedición libertadora del Perú, y en los años de 1825-1826, en la conquista de Chiloé ${ }^{44}$. Era hermano de Joaquín Campino, que había sido ministro de Freire entre el 8 de octubre de 1825 y el 7 de marzo de $1826^{45}$.

Barros Arana subraya que Campino era un "militar de malos antecedentes que, si bien se había incorporado en el ejército en los primeros días de la revolución, había sido separado de él en tres ocasiones por faltas graves y por su espíritu indisciplinado" ${ }^{46}$. Virgilio Figueroa es de la misma idea: "La vida del general Campino está rodeada de un ambiente de revuelta, de indisciplina y de rebelión contra las autoridades superiores. Era de genio turbulento, arrebatado y levantisco". Y agrega que llegó a ser diputado gracias al prestigio adquirido en la conquista de Chiloé: "Libre ésta y copartícipe él de sus laureles, quiso disfrutar del poder, subir

\footnotetext{
42 Ibídem, p. 96.

${ }^{43}$ Sesiones de los Cuerpos Legislativos, vol. XII, p. 8. Alejandro San Francisco ha demostrado que esta situación fue así durante todo el siglo XIX, incluso desde el período conservador: "Prácticamente no hubo periodo legislativo donde no hubiera al menos un miembro del ejército, habitualmente general de la república, cono senador o diputado. La tendencia comenzó ya en la década de 1830 y estuvo vigente hasta la de 1880, cuando la ley de incompatibilidades parlamentarias impidió la pertenencia simultánea al ejército y al congreso". San Francisco, Alejandro. 2010. La Guerra Civil de 1891. La irrupción política de los militares en Chile, vol. 1, Santiago, Centro de Estudios Bicentenario, p. 62.

${ }^{44}$ Figueroa, Pedro. 1897. Diccionario biográfico de Chile, vol. I, Santiago, Imprenta y Encuadernación Barcelona, p. 284.

45 Valencia, Luis. 1951. Anales de la República. Textos constitucionales de Chile y registro de los ciudadanos que han integrado los poderes ejecutivo y legislativo de 1810, vol. I, Santiago, Imprenta Universitaria, p. 293.

${ }^{46}$ Barros, Diego. Historia general de Chile, vol. XV, p. 99.
} 
a las alturas y ser un émulo de O'Higgins y de Freire, pero sus propósitos fracasaron” ${ }^{47}$. Estas referencias resultan interesantes, puesto que tanto Barros Arana como Figueroa reducen el militarismo a las características personales de sus protagonistas más bien que al carácter estructural que ese fenómeno asumía.

Para llevar a cabo el alzamiento, Campino se coordinó con el coronel Diego Guzmán y los sargentos mayores Francisco Paula Latapiat, Tadeo Quezada y José María Manterola. En ese momento, las unidades militares de la capital se reducían a dos: el batallón № 7 de infantería, creado el 25 de octubre de 1820, y el escuadrón de caballería Guías, fundado el 1 de abril de $1822^{48}$. La sublevación se inició la noche del 24 de enero. El coronel Ambrosio Acosta insubordinó a los Guías, que estaban bajo su mando. Luego, poniéndole una pistola al pecho al general Francisco Calderón ${ }^{49}$, el mismo Campino logró de este una orden que le fue entregada al mayor Nicolás Maruri ${ }^{50}$, quien estaba a cargo del batallón № 7, ya que su comandante, José Rondizzoni, se encontraba ausente. De esta manera, todas las unidades de Santiago se pusieron rápidamente bajo las órdenes de Campino.

Esa misma noche fueron apresados en el cuartel de San Diego el teniente coronel Tomás Obejero (ministro de Guerra interino) ${ }^{51}$, Manuel José Gandarillas (ministro del Interior), Juan de la Cruz Gandarillas (hermano del ministro), José Santiago Luco (intendente de Santiago), Fernando Elizalde (fiscal) y Diego Portales, quien — según Mariano Egaña, valga recordar- era muy cercano al gobierno. A la mañana siguiente y después de erigirse como Jefe de Estado, Campino hizo publicar una proclama que buscaba tranquilizar al pueblo sobre los propósitos de su acción:

"He podido infundir temores sobre vuestra seguridad individual, la de vuestra propiedad, y la conservación de los derechos que como hombres libres os competen; pero estad seguros de que jamás me habría puesto a la cabeza de la fuerza armada, si aun remotamente hubiese creído que al más mínimo de los conciudadanos se iba a inferir el más pequeño mal” ${ }^{52}$.

Esa misma mañana se reunió el congreso con carácter urgente. Concha y Toro es enfático en señalar que, además de Campino, el alzamiento era apoyado por otros diputados federalistas, especialmente Santiago Muñoz Bezanilla, Juan Fariñas, José María Novoa y Francisco Fernández: “A juzgar por los documentos que quedan de este suceso, el plan consistía

\footnotetext{
${ }^{47}$ Figueroa, Virgilio. 1925. Diccionario histórico y biográfico de Chile 1800-1825, vol. II, Santiago, Imprenta y Litografía La llustración, p. 320.

${ }^{48}$ Estado Mayor General del Ejército. 1980. Historia del Ejército de Chile, vol. III, Santiago, pp. 100-101.

49 Para sus datos biográficos, ver Figueroa, Diccionario histórico y biográfico de Chile, vol. II, p. 315.

${ }^{50}$ Como biografía breve de este personaje, ver Estado Mayor General del Ejército de Chile. 1981. Héroes y soldados ilustres del Ejército de Chile, Santiago, pp. 83-88.

${ }^{51}$ Luis de la Cruz, ministro en propiedad, se encontraba en ese momento enfermo.

52 Citado por Barros Arana, Historia general de Chile, vol. XV, p. 100.
} 
en echar abajo al poder ejecutivo y hacer que el congreso eligiese nuevo presidente" ${ }^{53}$. Barros Arana es más cauto: "Aunque algunos [de los diputados] simpatizaban con el movimiento revolucionario, y seguramente habían tenido parte en prepararlo, nadie se mostraba dispuesto a su favor" 54 .

¿Qué sucedió el día 25? Después de destituir al presidente Eyzaguirre, Campino se instaló en el palacio de gobierno y se apoderó de la cantidad de nueve mil pesos que distribuyó entre la tropa con el objeto de cancelar los sueldos atrasados ${ }^{55}$. Desde ese lugar, envió al Congreso a Nicolás Maruri, quien se desligó de toda responsabilidad, centrándola en Campino. El Congreso designó una comisión integrada por José Miguel Infante y Juan Fariñas, quienes concurrieron al palacio de gobierno a hablar con el coronel y colega diputado. Pero "Campino, colocado bajo el dosel del presidente, recibió a los comisionados más bien como hombre que dicta condiciones, que como el que está dispuesto a entrar en un avenimiento" 56 .

Concha y Toro, Claudio Gay y Barros Arana concuerdan que luego Campino se dirigió a caballo al Congreso. Pero sólo el tercero es explícito en que habría entrado de esta manera a la sala de sesiones 57: "Seguido por una compañía de fusileros, se presentó a caballo en el patio del congreso, y a caballo penetró a la sala de sesiones, dándole con voz imperiosa la orden de disolverse inmediatamente" ${ }^{\prime 58}$.

Concha y Toro afirma que el presidente del Congreso, Diego Antonio Elizondo, se mostró indiferente y que, incluso, le llegó a ofrecer asiento a Campino, lo que revela que "de seguro simpatizaba con el movimiento" 59 . Sin embargo, el acta de la sesión del 25 señala que "el señor presidente de la sala sostuvo la dignidad del cuerpo; hizo cargo al coronel Campino de los excesos cometidos, protestándole tendría que responder de ellos a la nación y a los pueblos" ${ }^{\prime 60}$. Además, y aunque de esto no da cuenta el acta de la sesión, la bibliografía coincide en que Diego José Benavente fue quien se mostró más categórico en contra de Campino. Lo cierto es que, al no lograr la disolución del parlamento, el coronel se retiró de la sala dejando a los otros oficiales a cargo de desocuparla. Al mando del coronel Latapiat, los soldados apuntaron sus

\footnotetext{
${ }^{53}$ Concha y Toro, Chile durante los años de 1824 a 1828, p. 163.

${ }^{54}$ Barros Arana, Historia general de Chile, vol. XV, p. 100.

55 Gay, Claudio. 2007. Historia física y política de Chile, vol. VIII, Santiago, Biblioteca Fundamentos de la construcción de Chile\&Pontificia Universidad Católica de Chile\&Biblioteca Nacional, p. 25. Esta obra fue originalmente publicada en 1848.

${ }^{56}$ Concha y Toro, Chile durante los años de 1824 a 1828, p. 164.

57 Concha y Toro hace referencia a que se presentó a caballo en el patio del congreso: "Habiéndose retirado la comisión sin lograr su objeto, Campino montó a caballo, se dirigió al congreso y desde la puerta de la sala intimó al presidente Elizondo que disolviera la asamblea". Concha y Toro, Chile durante los años de 1824 a 1828, 164. Gay describe este episodio como sigue: "Algunos momentos después, montado a caballo, se dirigió al congreso y se presentó en el salón de las sesiones". Gay, Historia física y política de Chile, vol. VIII, p. 26.

58 Barros Arana, Historia general de Chile, vol. XIV, p. 100.

${ }^{59}$ Concha y Toro, Chile durante los años de 1824 a 1828, p. 164.

${ }^{60}$ Sesiones de los Cuerpos Legislativos, vol. XIV, p. 64.
} 
fusiles a los diputados de manera amenazante. En ese instante, todos se retiraron de la sala, salvo Benavente, "que con la mayor sangre fría y entereza permaneció en su puesto" ${ }^{61}$. Sin apoyo civil, los militares no se atrevieron a apretar el gatillo. Luego de que los soldados se retiraron del Congreso, los diputados retornaron a la sala y aprobaron el siguiente proyecto de acuerdo:

“Artículo primero. El capitán general don Ramón Freire se encargará del mando político y militar de la república hasta que se elija otro por el congreso.

Art. 2ㅇ El congreso corre un velo a los sucesos acaecidos en la noche del 24 y día del 25 , protestando un eterno olvido para sus autores.

Art. 3o Posesionado del mando, decretará la libertad de los individuos que se hallan en arresto, mandándoles comparecer y encargándoles, por el bien de la nación, un absoluto olvido de sus agravios" ${ }^{62}$.

Como se observa, mientras se confiaba (otra vez) en el prestigio militar de Freire, se aprobaba también una amnistía inmediata en favor de los implicados. No deja de ser llamativo que lo segundo se hiciese antes, incluso, de controlar el alzamiento mismo. Al parecer, los diputados pensaron que de esta manera los rebeldes se someterían con mucha mayor facilidad. Sin embargo, y después varios intentos infructuosos de negociación, el asunto terminó resolviéndose por la acción "contrarrevolucionaria" del grupo estanquero ${ }^{63}$.

Diego José Benavente, quien se encontraba oculto en la casa de un amigo, contactó a Nicolás Maruri, quien aceptó liderar la represión de los sublevados. En la madrugada del lunes 29, apresó a Campino, Guzmán, Latapiat, entre otros jefes, y puso en libertad a los prisioneros políticos. Según Concha y Toro, "Maruri recibió de don Diego Portales, por mano de don Enrique Newman, tres mil pesos para gratificar a la tropa y oficialidad"64. Freire -que ya había reunido a 1.200 hombres-, al enterarse de la contrarrevolución liderada por Maruri, se puso en marcha sobre la capital, llegando el día 30. Ya en Santiago, mantuvo en sus cargos ministeriales a Manuel José Gandarillas (en Interior) y al teniente coronel Tomás Obejero (en Guerra). Además, ordenó "que los tribunales correspondientes formasen causa a los autores del motín, para que sean escarmentados del modo que previenen las leyes" ${ }^{65}$. Sin embargo, Campino invocó su calidad de diputado y, por lo tanto, su fuero parlamentario.

\footnotetext{
61 Concha y Toro. 1862. Chile durante los años de 1824 a 1828, p. 165.

62 Sesiones de los Cuerpos Legislativos, vol. XIV, p. 65.

63 Liderado por Diego Portales, los miembros de este grupo creían en un gobierno autoritario y centralizado que pusiese término a la anarquía. Formaban también parte de este grupo Manuel José Gandarillas, Diego José Benavente, Manuel Rengifo, entre varios otros.

${ }^{64}$ Concha y Toro, Chile durante los años de 1824 a 1828, p. 169.

${ }^{65}$ Sesiones de los Cuerpos Legislativos, vol. XIV, p. 94.
} 
Este tema se discutió apasionadamente en las primeras sesiones del mes de febrero. El día 7 el diputado Ignacio Molina presentó una moción destinada a garantizar la amnistía a los implicados en la sublevación del 24 de enero. Argumentó que le parecía injusto que los contrarrevolucionarios, que inicialmente habían tomado parte en el alzamiento, fuesen amnistiados, y no así quienes se mantuvieron sublevados hasta el final. También recordó que, por el bien de la patria, los rebeldes de Chiloé, del año anterior, habían sido también amnistiados. Pero el argumento más llamativo guardaba relación con el estado que vivía el país:

"Por otra parte, en un país inconstituido, donde tampoco hay una ley preventiva de la pena a que se hace acreedor el que o los que obran en estos casos a mano armada, que podrá decírseles a aquéllos que al hacer una conmoción toman por protesto. No hay gobierno; todos lo saben. No hay leyes, ¿quién lo ignora? La patria está sobre el borde de un precipicio, es innegable. Tardío e inútil es el remedio que en esa dislocación absoluta se quiera aplicar por las vías legales; quien conoce la revolución dirá que este es un axioma inconcuso" 66 .

Finalmente, el 8 de febrero (pero con fecha 12 del mismo mes en honor al aniversario de la Independencia) ${ }^{67}$ se concedió la "amnistía a los ciudadanos comprendidos en el movimiento de la noche del 24 de enero y siguientes", pero otorgándole al nuevo Presidente de la República, Ramón Freire, la facultad de separarlos de Santiago por el tiempo que considerase necesario ${ }^{68}$. Este hecho revela al menos dos cosas. Primero, la tolerancia a la violencia como método de acción política. Y segundo, la aceptación de que los militares podían actuar -aunque ello no se consideraba un ideal - en favor o en contra de tal o cual bando político. Esto último revela el carácter partidista más bien que corporativo del militarismo de la década de 1820 .

Ahora bien, a la luz de los hechos referidos, volvamos sobre la pregunta de si el alzamiento de Campino tuvo o no, y hasta qué punto, un carácter federalista. Quizás sea necesario aquí distinguir dos aspectos claves: a) si dicho alzamiento persiguió la dictación de una Constitución federalista; y b) si participaron (al menos, desde las sombras) integrantes del grupo federalista. Sobre el primer aspecto, cabe recordar que, en el caso del alzamiento de Campino, ya se estaban aplicando un conjunto de leyes federales de julio de 1826, especialmente asociadas a las elecciones de distintas autoridades. Sobre el punto b), y a la luz de diversas fuentes consultadas, no se aprecia en Campino y sus acompañantes un ideario político abiertamente federalista, sino más bien pragmático. De hecho, el 19 de enero de 1827 -unos pocos días antes del alzamiento que lideró- se había ingresado el proyecto de Constitución federal, por

\footnotetext{
66 Ibíd., p. 101.

67 En esa época, la Independencia se celebraba en conmemoración de la batalla de Chacabuco, acontecida el 12 de febrero de 1817.

${ }^{68}$ Sesiones de los Cuerpos Legislativos, vol. XIV, p. 105.
} 
lo que incluso podía resultar contraproducente una acción de fuerza destinada a asegurar su promulgación.

Más que bajo la etiqueta de federalista, el alzamiento de Campino es posible insertarlo en la lucha entre las dos grandes tendencias del periodo. Precisamente la inestabilidad política reinante, atestiguada por personajes de distintos bandos, había aumentado la polarización entre liberales y conservadores. Entre quienes defendían la consagración de un régimen descentralizado y de mayores libertades políticas, y quienes abogaban por una autoridad fuerte, capaz de restaurar el orden público. Bajo este contexto, la segunda mitad de 1826 había consolidado al grupo estanquero, coincidiendo con el cierre del estanco del tabaco de que había gozado la firma Portales, Cea y compañía. En torno a Portales, se habían aglutinado Diego José Benavente y Manuel José Gandarillas, entre otros. El segundo, ministro del Interior de Eyzaguirre, al momento del alzamiento de Campino. Y el mismo Portales, que según Barros Arana, había comenzado a actuar en la práctica como consejero del gobierno ${ }^{69}$.

Aunque carente de don de mando para enfrentar el contexto que se vivía - de crisis económica, desorden social, entre otros aspectos-, Agustín de Eyzaguirre pertenecía al grupo pelucón y era visto por los federalistas como un obstáculo para la instauración definitiva del régimen federal. Sin embargo, y no obstante que sea plausible pensar en un apoyo tácito de los parlamentarios federalistas a la acción de Campino, esta investigación no ha logrado probar la tesis de Concha y Toro, referida a que varios de ellos estuvieron directamente involucrados -aunque de manera solapada - en el alzamiento.

En todo caso, en el marco de la lucha más amplia entre liberales y conservadores, que caracterizó la década de 1820 en Chile, resulta mucho más claro que la sublevación de Enrique Campino iba dirigida contra el grupo estanquero. No por nada Portales fue apresado de manera inmediata, junto a algunas de las autoridades de gobierno. $Y$ en el caso de Benavente, pese al arrojo demostrado en el congreso el día 25, después tuvo que esconderse en la casa de un amigo. Desde ese lugar, realizó tratativas con Maruri con el objeto de generar una contrarrevolución. Por lo demás, el 30 de enero de 1827, el mismo día del retorno de Freire a la capital, Portales se dirigía a Freire en los siguientes términos:

"Las circunstancias peligrosas en que nos hallamos no me permiten abstenerme de dar este paso. Una sola hora que usted demore puede importar una nueva revolución. En estos momentos críticos no hay quien tome una sola medida de seguridad, y se está dejando libre el campo a los enemigos del orden, que hacen nuevos esfuerzos para perturbarlo" 70 .

\footnotetext{
69 Barros Arana, Historia general de Chile, vol. XV, 99.

70 Fariña, Carmen. 2007. Epistolario Diego Portales (1833-1837), vol. I, Santiago, Ediciones Universidad Diego Portales, p. 60.
} 
Este parece ser el momento en que Portales se decidió a avanzar hacia un régimen autoritario, capaz de imponer el orden de manera sistemática. Queda pendiente estudiar el militarismo del propio Portales. Pero, además de haber comenzado en la década de 1820, en los eventos referidos en esta sección, luego se extendió a la sublevación de 1829 y al militarismo estatal de los decenios conservadores. Como esta autora ha señalado en otro lugar:

"[...] se suele olvidar que Portales, quien muchas veces ha sido presentado como 'civilista" ${ }^{71}$, contó siempre con sus propios militares. No solo en la guerra civil de 1829, iniciada por las fuerzas castrenses de Concepción, sino también cuando el bando pelucón logró conquistar el gobierno. Desde ese instante, en efecto, los militares estuvieron más fuertemente controlados por los gobiernos que se sucedieron, pero no para ponerlos al servicio del conjunto del país, sino para utilizarlos como fuerza política en contra de la oposición"72.

\section{El alzamiento de Pedro Urriola de 28 de junio de 1828}

El contexto político en que se inserta el alzamiento de Urriola está representado por el gobierno de Francisco Antonio Pinto, quien ejercía el mando supremo en calidad de vicepresidente, y a quien le había correspondido suceder a Freire desde el 5 de mayo de 1827. En términos constitucionales, a Pinto le correspondió llevar a cabo la difícil tarea de derogar el sistema federal. Este proceso se expresó en la dictación de una ley - de fecha 19 de junio de 1827-, cuyo artículo 10 estableció un procedimiento de consulta "a las provincias por medio de sus asambleas la forma de gobierno por que debía constituirse la república". A través del artículo 4ㅇs se estableció la disolución del Congreso y el nombramiento de "una comisión autorizada para remitir la consulta a las provincias, y aprobar o reprobar las proposiciones que presente el poder ejecutivo"73.

En pocas palabras, este nuevo organismo - llamado Comisión Nacional- se encargaría de dirigir el proceso de derogación del federalismo. De hecho, el 2 de agosto Pinto dictó una ley que suspendió las elecciones de intendentes, gobernadores y párrocos, aunque conservando las de los cabildos ${ }^{74}$. Al día siguiente de esa ley, Pinto designó como intendente propietario de la provincia de Colchagua al coronel José Francisco Gana ${ }^{75}$. Sin embargo, los cabildos de Curicó y San Fernando, que preferían seguir únicamente en manos de sus autoridades locales, no

\footnotetext{
${ }^{71}$ Rojas, Gonzalo. 1989. "Portales y la seguridad interior del Estado", en Bernardino Bravo Lira (compilador), Portales. El hombre y su obra la consolidación del gobierno civil, Santiago, Editorial Jurídica de Chile \& Editorial Andrés Bello, pp. 55-86.

72 Verbal, Valentina, "De hermana mayor a madre protectora", p. 204.

${ }_{73}$ Sesiones de los Cuerpos Legislativos, vol. XIV, p. 441.

${ }^{74}$ Sesiones de los Cuerpos Legislativos, vol. XV, p. 34.

75 Como biografía breve de este personaje, ver González Salinas, Edmundo. 1963. Soldados ilustres del Ejército de Chile, Santiago, Estado Mayor del Ejército, pp. 54-57.
} 
aceptaron el nombramiento de Gana. En la práctica, la provincia de Colchagua siguió estando gobernada por autoridades independientes, sin la existencia de ninguna común: Feliciano Silva, como gobernador local de San Fernando, e Isidoro Peña, al mando de Curicó ${ }^{76}$.

Como se observa, al igual que en el caso de San Felipe - visto más arriba -, en San Fernando existía una fuerte lucha de poder entre los distintos liderazgos locales. Al darse cuenta de que la asamblea provincial, que aún seguía funcionando - aunque no con tanta regularidad-, no lo apoyaba, Feliciano Silva tomó la decisión de ordenar el apresamiento de algunos cabecillas del bando contrario. Esta situación - acontecida durante los días 31 de diciembre de 1827 y 1 de enero de 1828- dio por resultado el alzamiento de una unidad de milicianos, comandados por Francisco Porras. Aquí nuevamente puede apreciarse la existencia de un militarismo social, como complemento de un militarismo propiamente político.

El Valdiviano Federal - periódico fundado por José Miguel Infante el 1 de diciembre de $1827^{77}$, siendo él mismo su principal redactor - cubrió con bastante detalle los sucesos de San Fernando, tomando claro partido en favor de los sublevados. Leamos la siguiente cita:

“¿Queremos acaso obligar a los pueblos a una ciega deferencia propia de los esclavos? He ahí el resultado. Después que sumisamente reclaman el cumplimiento de las leyes que les son benéficas, si se les desatiende no les queda otro recurso que el de la fuerza, o el de la sumisión servil. El primero cuesta sacrificio, pero en favor de la libertad. El segundo es más funesto que la misma muerte" 78 .

Con el objeto de restablecer el orden público, el 5 de enero fue nombrado como intendente interino el teniente coronel José Patricio Castro, comandante del batallón № 6 (Maipo) ${ }^{79}$. Después de una negociación, que produjo una aparente tranquilidad, los problemas se revivieron en marzo siguiente. Feliciano Silva - que había reasumido el cargo de gobernador local de San Fernando- decidió, el 27 de marzo, tomarse con algunos militares y vecinos, el cuartel de San Francisco; "y desde allí mantuvo durante dos horas un sostenido fuego, que impedía a los facciosos intentar el asalto" ${ }^{80}$. Al ser incapaces de hacerse de la ciudad, los rebeldes se retiraron hacia los campos, desde los cuales siguieron (por un tiempo) actuando como guerrilleros. El 14 de abril en la noche atacaron la ciudad de Rancagua y lograron apoderarse de algunas armas ${ }^{81}$.

\footnotetext{
${ }^{76}$ Barros Arana, Historia general de Chile, vol. XV, p. 170.

77 Ver Silva, Raúl. 1958. Prensa y periodismo en Chile (1812-1956), Santiago, Ediciones de la Universidad de Chile, p. 89.

${ }^{78}$ El Valdiviano Federal, № 5, Santiago, 4 de enero de 1828, p. 4.

79 Barros Arana, Historia general de Chile, vol. XV, 170.

80 Ibíd., p. 171.

81 Ibídem.
} 
Este fue el escenario propicio para el alzamiento de la noche del 28 de junio de 1828, liderado por el coronel Pedro Urriola. Gay describe a este personaje como un "joven arrojado y de gran corazón, a quien la naturaleza, al negarle el don del discernimiento y la prudencia, lo había dotado, en cambio, de un carácter ligero y amigo de aventuras, cualidades que los ambiciosos supieron poner a su servicio y explotarlas en aquellas difíciles y peligrosas circunstancias" ${ }^{82}$. Otra vez puede apreciarse la asociación del militarismo a las características psicológicas de sus protagonistas más bien que a un contexto estructural que lo favorecía.

En todo caso, una particularidad personal de Urriola - a diferencia de Campino- es que, además de no poseer mando de tropa, se encontraba fuera del servicio activo. Según Barros Arana, "Urriola vivía en Requínoa, en la hacienda de su suegro don Francisco Valdivieso, que era uno de los más acaudalados propietarios de la comarca; y desde allí había mirado con indiferencia los tumultuosos acontecimientos de los meses anteriores" $" 83$.

Por otra parte, existe un cierto debate historiográfico - sobre el que se volverá más adelante-acerca de la real motivación política de Urriola. Mientras que Gay afirma que era “uno de los más locos entusiastas de O’Higgins, a quien consideraba como el único hombre capaz de constituir el país" 84 , Barros Arana sostiene que estaba impulsado "por los federalistas de Santiago, y persuadido de que estos preparaban un levantamiento revolucionario en varias provincias", por lo cual resolvió a ponerse a la cabeza del alzamiento que debía producirse en Colchagua" 85 ,

Lo concreto es que este personaje se dirigió a San Fernando, logrando la adhesión del batallón № 6, especialmente del sargento mayor José Antonio Vidaurre ${ }^{86}$. En la noche del 28 de junio, los rebeldes arrestaron al intendente José Patricio Castro y al comandante de milicias, Francisco Ibáñez. A la mañana siguiente, el cabildo de la ciudad - reunido con ese preciso objeto- proclamó a Urriola como nuevo intendente de la provincia. Detrás de este nombramiento se encontraba la mano de Feliciano Silva, caudillo local, ya mencionado. Apenas se enteró de estos acontecimientos, el vicepresidente Pinto buscó negociar, pero al constatar la negativa tajante de Urriola, optó por enviar una fuerza dirigida por el mismo ministro de Guerra, general José Manuel Borgoño. Fuerza en la que también participó Guillermo de Vic Tupper, quien el 7 de julio escribía en su Diario de Campaña:

\footnotetext{
82 Gay. Historia física y política de Chile, p. 67. Barros Arana afirma que Claudio Gay constituye una fuente primaria fundamental de este alzamiento, ya que, "tres años después, recogió en San Fernando, y de boca de los mismos autores, informes sobre estos acontecimientos". Barros Arana, Historia general de Chile, vol. XV, p. 181.

83 Barros Arana. 2005. Historia general de Chile, vol. XV, p. 180.

${ }^{84}$ Gay. Historia física y política de Chile, p. 67.

85 Ibídem, 68.

${ }^{86}$ El mismo que años más tarde - el 3 de junio de 1837- se rebelará contra Diego Portales, provocando su muerte. Como biografía breve de este personaje, ver Figueroa, Diccionario biográfico de Chile, 473-475.
} 
"Se cree generalmente que el objeto de esta sublevación sea el llevar a don José Miguel Infante a la Presidencia de la República. La desenfrenada ambición de este hombre no permite titubear que él aprovecharía de un motín militar para colocarse en la cima del gobierno, aunque para llegar allí tuviera que pasar por encima de los cadáveres de la mitad de sus conciudadanos" 87 .

Mientras Borgoño y Tupper se distraían en San Fernando, las tropas de Urriola se dirigieron a la capital. Al enterarse de esta situación, Borgoño decidió apurar el tranco con el objeto de cortarles el paso. Pero esto no fue posible. Borgoño, al constatar la disparidad de fuerzas que poseía en comparación con las de Urriola, en vez de entrar a Santiago, decidió seguir su marcha hacia Valparaíso con el objeto de ponerse a disposición del Congreso, que en ese momento sesionaba en dicho puerto ${ }^{88}$. Hay que considerar que de acuerdo a la mentalidad política de la época, el poder legislativo poseía tanto o más peso que el ejecutivo. Dice, a este respecto, Julio Heise: "La preeminencia, la superioridad del parlamento será el gran principio político del mundo occidental hasta las primeras décadas de nuestro siglo (el XX). Tengamos presente que el constitucionalismo clásico nació como una reacción contra el absolutismo". ${ }^{89}$

De esta manera, el vicepresidente Pinto se vio en la obligación de enfrentar por su cuenta, a los sublevados con las pocas fuerzas con que contaba, "unos cuatrocientos hombres de la Guardia Nacional, imperfectamente armados, y de muy escasa instrucción, y cien coraceros de la escolta presidencial; y poniéndose él mismo a su cabeza salió a colocarse en las afueras del sur de la capital, en el sitio denominado chacra de Ochagavía" ${ }^{90}$. Esta batalla -acontecida el 18 de julio y que resultó ser una completa derrota para las fuerzas gobiernistas - no trajo consigo, sin embargo, el inmediato derrocamiento de Pinto. No resulta menor notar que, de acuerdo a una suscripción en beneficio de las viudas, puede, al menos, hablarse de la cifra 838 muertos y 547 heridos. ${ }^{91}$ Este es un ejemplo, entre otros, de que el periodo 1823-1830 no fue tan pacífico, como a veces se suele insinuar, sino justamente todo lo contrario.

Ya en la capital, Urriola solicitó una reunión a la asamblea provincial de Santiago, nombrando como sus apoderados a Infante, Pradel y Magallanes, todos federalistas. En dicha reunión, efectuada la noche del 19 de julio, Infante pronunció un extenso discurso, en el que señaló que

\footnotetext{
87 Vic de Tupper, Guillermo. 1972. “Diario de Campaña”, en Ferdinand B. Tupper, Memorias del coronel Tupper (18001830), Buenos Aires, Editorial Francisco de Aguirre, pp. 154-155.

88 Barros Arana, Historia general de Chile, vol. XV, 184.

89 Heise, Julio. 1974. Historia de Chile. El periodo parlamentario. 1861-1925, vol. I. fundamentos histórico-culturales del parlamentarismo chileno, Santiago, Editorial Andrés Bello, p. 11.

${ }^{90}$ Barros Arana, Historia general de Chile, vol. XV, 184.

91 Ibíd., p. 184, nota al pie № 17.
} 
"los diversos movimientos revolucionarios que se venían experimentando desde hace un año y medio atrás, así en Santiago como en las provincias, no eran producidos por ambiciones mezquinas y bastardas de determinados caudillos, sino por la aspiración justa y generosa de los pueblos por ver constituida la nación bajo un régimen de libertad [¿ifederal?] capaz de hacerla feliz" ${ }^{\prime 2}$.

Al día siguiente, Urriola instaló sus tropas en la misma Plaza de $\operatorname{Armas}^{93} \mathrm{y}$, mediante un bando, nombró a José Miguel Infante como "supremo interventor de la república con las facultades que son inherentes al presidente del Estado, quien cuidará a la mayor brevedad de expedir una convocatoria a las provincias para que se reúnan por medio de diputados electos libremente y den la Constitución al país"94. Sin embargo, ni Infante aceptó dicho cargo ni tampoco las tropas sublevadas se atrevieron a entrar al palacio para deponer físicamente el vicepresidente Pinto. ¿Por qué sucedió esto? ¿Por qué, a diferencia del caso de Campino y de otras sublevaciones, el alzamiento de Urriola no llegó al límite de hacerse con el gobierno?

Estas preguntas se relacionan con la tercera interrogante planteada en esta investigación: ¿por qué no llegaron esos alzamientos (también el de Campino) a "buen término", en el sentido de derrocar a los gobiernos a los que se enfrentaron? En el caso de Urriola, una respuesta puede encontrarse en la persistente negativa de Infante de pactar con las fuerzas armadas. De hecho, cuando Urriola buscó su consejo, el líder federalista se negó "por mi innata propensión a evitar compromisos con la fuerza armada" ${ }^{95}$. Una segunda respuesta, complementaria a la anterior, puede hallarse en la gran cantidad de personas (alrededor de tres mil) que se reunieron en la misma plaza en apoyo del gobierno ${ }^{96}$. Gay señala que muy luego "las tropas se convencieron de la peligrosa situación en que se hallaban, al ver que, a los gritos de iviva Infante!, lanzados por algunas personas de entre la muchedumbre, ésta en su mayor parte contestaba con los de iviva Pinto y viva el pueblo!"97.

Esta sensación llevó al gobierno a llamar a palacio a José Antonio Vidaurre, quien comandaba las tropas situadas en la plaza. El 22 de julio -y ya absolutamente convencidos de la falta de apoyo popular a la sublevación - Vidaurre y Daniel Cason, comandantes del batallón Maipú y regimiento de Dragones, respectivamente, expresaron su arrepentimiento e imploraron al gobierno su perdón:

\footnotetext{
92 Barros Arana, Historia general de Chile, vol. XV, 184.

${ }^{93}$ Valga aclarar que, en ese tiempo, la casa de gobierno funcionaba en dicho lugar, en el actual edificio de Correos de Chile.

${ }^{94}$ Citado por Barros Arana, Historia general de Chile, vol. XV, p. 188. Énfasis añadido.

${ }^{95}$ El Valdiviano Federal, № 19, Santiago, 2 de agosto de 1828, p. 4.

${ }^{96}$ Barros Arana. Historia general de Chile, vol. XV, p. 188.

${ }^{97}$ Gay. Historia física y política de Chile, vol. VIII, p. 69.
} 
“El batallón Maipú y el regimiento de Dragones, conociendo la enorme falta que han cometido, se arrepienten sinceramente de ella y penetrados de dolor ocurren a la paternal piedad de V. E. implorando el perdón. Si V. E. recuerda los heroicos servicios que han prestado a la patria, la miseria de que se han visto rodeados, y la situación política del país, que es casi imposible evitar que afecte a las tropas, no trepidará en concederlo y en acoger benigno a unos hijos extraviados que vuelvan a su deber" 98 .

Ese mismo día, el gobierno emitió un decreto de amnistía en beneficio de todos los implicados, incluyendo expresamente a Pedro Urriola (artículo 5ㅇ); pero aclarando que: "Cualquier otro movimiento militar que pudiese ocurrir en lo sucesivo, será irremisiblemente castigado con todo el rigor de las leyes" (artículo 60) ${ }^{99}$. El 31 de julio Tupper señalaba: "De este modo, han concluido todas las sublevaciones en Chile. Y por este motivo hay cada año, ya sea puramente militar como ésta o suscitada por medio de pobladas de facciosos, acompañados de los votos de la capital" ${ }^{100}$. Esta sentencia de Tupper da cuenta de lo señalado anteriormente: las fuerzas políticas de la época partían de la base que los militares podían constituirse en herramientas políticas al servicio de tal o cual bando ideológico.

Por otra parte, a diferencia del caso de Campino, el alzamiento liderado por Urriola sí contó con una mayor participación del grupo federalista, pero no con el objetivo claro de instaurar un régimen que estaba siendo derogado. A la luz de las fuentes referidas, el mismo Infante cumplió un rol protagónico. No en la sublevación misma, pero sí en la búsqueda de una solución. No obstante que, podría suponerse que se le consultó en torno a su nombramiento como "supremo interventor de la república", la presente investigación no ha encontrado algún documento que acredite la participación directa de Infante en el alzamiento ${ }^{101}$. Sin embargo, resulta claro que Infante simpatizó con la sublevación contra el gobierno de Pinto. No es para menos, ya que no fue sino Pinto quien estaba llevando a cabo la derogación de la obra que, con tanto fervor, el líder federalista había antes impulsado.

Por lo demás, el carácter finalmente fallido de la sublevación de Urriola no se debió a la falta de fuerzas militares - que, como ya se vio, habían logrado derrotar a las del gobierno-, sino por no haber contado con suficiente apoyo de las elites civiles. Pero, sobre todo, y de manera particular, por el hecho de que el mismo Infante se negó a asumir la primera magistratura a través de un golpe de fuerza. Parece bastante claro que la indecisión de Infante fue la razón principal que impidió que las fuerzas castrenses, acantonadas en la Plaza de Armas, entrasen al palacio de gobierno y destituyesen a Pinto. ¿Por qué Infante no se atrevió a dar ese paso? ¿Por

\footnotetext{
98 Sesiones de los Cuerpos Legislativos, vol. XVI, p. 239.

99 Ibídem.

100 Tupper. “Diario de Campaña”, p. 161.

101 La bibliografía secundaria citada en este artículo tampoco da cuenta de dicha participación.
} 
qué no apoyó con mayor decisión el golpe final de Urriola? Probablemente, porque sabía que ninguno de ellos contaba con suficiente apoyo de las elites civiles. En efecto, las actas de las sesiones del poder legislativo dieron cuenta de un mayoritario apoyo al gobierno en desmedro del grupo federalista, que simpatizaba con el alzamiento. Por ejemplo, en la sesión del 22 de julio se aprobó el siguiente proyecto de acuerdo:

“Cualquiera que sea el resultado de tales preliminares, la nación será deudora al gobierno y al gran pueblo de Santiago de la heroica firmeza con que han evitado la degradación y envilecimiento a que quisieron precipitarla manos pérfidas e ingratas; pero así como ella no sabrá economizar los efectos de su reconocimiento al patriotismo y a la virtud de los que se han sacrificado por salvarla, hará sentir el formidable peso de su indignación a los que pertinazmente se empeñen en destruirla y a los que, ajenos de todo sentimiento elevado, no se rindan al sublime ejemplo que han recibido de los verdaderos chilenos, y labren todavía otras desgracias a su patria". ${ }^{102}$

\section{Conclusiones}

Volvamos en esta parte final a leer las tres grandes preguntas planteadas en la introducción: a) ¿tuvieron, y hasta qué punto, los alzamientos estudiados un carácter federalista?; b) si en alguno u otro grado lo tuvieron, ¿puede la caída del proyecto federal reducirse meramente a su carácter "utópico", sin considerar el fracaso concreto de las sublevaciones estudiadas en el presente trabajo?; y c) ¿por qué no llegaron esos alzamientos a "buen término", en el sentido de derrocar a los gobiernos a los que se enfrentaron?

Como se dijo más arriba, no se aprecia en Campino una adhesión expresa al proyecto federalista. Su alzamiento, recordemos, tuvo lugar en momentos en que aún se estaban aplicando las leyes federales de 1826, en particular con respecto a la elección de diversas autoridades. Probablemente, Concha y Toro confunde simpatía con autoría. Que Santiago Muñoz Bezanilla y Juan Fariñas - por citar sólo dos ejemplos referidos por dicho autor- hayan simpatizado con la caída de Eyzaguirre es una cosa. Pero otra muy distinta es que hayan comandado - desde las sombras - el alzamiento liderado por Campino. A diferencia de la "revolución de Sánchez" de 1825, la participación del congreso en esta sublevación fue claramente accidental. Su actividad, por el contrario, estuvo orientada a detener la sublevación. Por mucho que Fariñas haya visto con buenos ojos la acción de Campino, resulta difícil pensar que él mismo haya sido parte de su trama, sobre todo si se toma en cuenta que integró una comisión negociadora frente a Campino.

Más que bajo la etiqueta de federalista, el alzamiento de Campino es posible insertarlo en la lucha - a sangre y fuego, incluso- entre liberales y conservadores, dentro de la cual había

102 Sesiones de los Cuerpos Legislativos, vol. XVI, p. 230. 
comenzado a adquirir protagonismo el bando estanquero. Aquí, como ya vimos, Portales comenzó a desarrollar su propio militarismo, uno que entendía a los militares ya no al servicio de distintos bandos políticos, sino únicamente del bando conservador para utilizarlo en contra de la oposición liberal (civiles y militares) durante los decenios conservadores, en particular bajo el gobierno de José Joaquín Prieto (1831-1841).

En cambio, el contexto del alzamiento de Urriola fue distinto, puesto que coincidió con un proceso de desmantelamiento del sistema federal. Además, en el caso de Urriola, hay que hacer algunas distinciones. En términos personales, formaba parte del grupo o'higginista, pero claramente la sublevación que encabezó en 1828 no tuvo el propósito de lograr el retorno de O’Higgins al poder. La verdad, este anhelo se había extinguido con la fallida sublevación de Chiloé de 1826. Sin embargo, en mayor medida que en el caso de Campino, contó con un abierto apoyo del grupo federalista, incluyendo al propio José Miguel Infante, el máximo líder de ese grupo político.

Además, y a diferencia del caso de Campino, el alzamiento liderado por Urriola contó con una mayor participación del grupo federalista. Como ya se vio, Infante cumplió un rol protagónico. Pero no en la sublevación, sino en la búsqueda de una solución. Su simpatía por el alzamiento de Urriola puede explicarse por el hecho de que Pinto estaba derogando el proyecto político que él había impulsado desde 1826.

¿Fracasó el federalismo en Chile por responder a la noción de constitucionalismo utópico, en los términos de Heise? Como la autora de esta investigación ha dicho antes, no cabe duda de que,

“a diferencia de los Estados Unidos - que buscó unir lo que antes estaba separado-, en Chile se buscó separar, un poco a la fuerza, no lo que estaba del todo unido (esto es cierto), sino lo que todavía - y ni siquiera - estaba suficientemente incorporado al territorio y administración del país. Porque, más allá de las tres provincias históricas —Santiago, Concepción y Coquimbo-, las otras que se reconocieron no estaban completamente incorporadas; y no solo a la estructura misma del Estado, sino sobre todo al quehacer público que en torno a él giraba. No habían, por ejemplo, participado de la seminal deliberación que, aunque conflictiva en muchos sentidos, significó el período de la Patria Vieja". ${ }^{103}$

En todo caso, muy discutible resulta la afirmación de que el ensayo federal fracasó por "culpa" exclusiva de un proyecto constitucional que ni siquiera entró a regir del todo (la carta misma nunca se alcanzó a aprobar), y no también por otros factores como el militarismo de la época. En el caso que nos ocupa, por el hecho de que las insubordinaciones castrenses no cumplieron con el objetivo de derrocar a los gobiernos a los que se enfrentaron. Por lo demás,

103 Verbal, Valentina, “De hermana mayor a madre protectora", p. 199. 
y como ya se vio, el fracaso final de la sublevación de Urriola se debió a la falta de apoyo de líderes civiles, especialmente de Infante, así como a la carencia de suficiente sustento popular. La falta de apoyo civil en favor de Urriola y del proyecto federal, liderado por Infante, confirma que el militarismo no suele dar cuenta de acciones corporativas, de los militares en contra de los civiles, sino de una coparticipación civil-militar, en favor o en contra de uno u otro bando en disputa.

Solamente a partir de la consideración precedente, puede entenderse la indecisión de las fuerzas sublevadas para dar el golpe final en contra del gobierno de turno. Al no contar con suficiente apoyo civil, ello resulta en la práctica imposible, pese a sentirse merecedoras de reconocimiento por los servicios prestados al país en los campos de batalla. Se trata de lo que Finer denomina "ineptitud moral de la intervención militar" ${ }^{104}$, y que consiste en la falta de apoyo de la opinión pública - de las elites civiles, en la época del presente estudio- para llevar a cabo la intervención castrense en contra de las autoridades legítimamente constituidas. En este sentido, se justifica plenamente la denominación de "oportunidades perdidas" para los alzamientos de 1827 y 1828.

\section{Referencias citadas}

\section{Fuentes primarias}

Amunategui S., Domingo. 1939. Pipiolos y Pelucones, Santiago, Imprenta y Litografía Universo.

Concha y Toro, Melchor de. 1862. Chile durante los años de 1824 a 1828. Memoria histórica leída en la sesión solemne de la Universidad de Chile el 12 de octubre de 1862, Santiago, Imprenta Nacional.

El Valdiviano Federal. 1828. № 5, Santiago, 4 de enero de 1828, p. 4.

El Valdiviano Federal. 1828. № 19, Santiago, 2 de agosto de 1828, p. 4.

Fariña V., Carmen. 2007. Epistolario Diego Portales (1833-1837), vol. I, Santiago, Ediciones Universidad Diego Portales.

Gay, Claudio. 2007. Historia física y política de Chile, vol. VIII, Santiago, Biblioteca Fundamentos de la construcción de Chile - Pontificia Universidad Católica de Chile - Biblioteca Nacional.

Letelier, Valentín. 1901. Sesiones de los Cuerpos Legislativos, vol. XII, XIII, XIV, XV XVI, Santiago, Imprenta Cervantes.

Tupper, Guillermo Vic de. 1972. "Diario de Campaña", en Tupper, Ferdinand B., Memorias del coronel Tupper (1800-1830), Buenos Aires, Editorial Francisco de Aguirre, pp. 93-163.

Valencia A., Luis. 1951. Anales de la República. Textos constitucionales de Chile y registro de los ciudadanos que han integrado los poderes ejecutivo y legislativo de 1810, vol. I, Santiago, Imprenta Universitaria.

${ }^{104}$ Finer, Los militares en la política mundial, pp. 33-34. 


\section{Fuentes secundarias}

Abdó Francis, Jorge. 2002. "Sistemas de distribución de atribuciones en los estados federales", en Serna de la Gaza, José María (coord.), Federalismo y regionalismo. Memoria del VII Congreso Iberoamericano de Derecho Constitucional, México D.F., Instituto de Investigaciones Jurídicas Universidad Nacional Autónoma de México, pp. 3-13.

Barros A., Diego. 2005. Historia general de Chile, vol. XIV, Santiago, Editorial Universitaria - Centro de Estudios Diego Barros Arana.

Carpizo, Jorge. 1973. Federalismo en Latinoamérica. México D.F., Instituto de Investigaciones Jurídicas Universidad Nacional Autónoma de México.

Cartes, Armando. 2018. "De época maldita a epopeya liberal. Una revisión historiográfica a la anarquía chilena (1823-1830)", en Illes i Imperis, N²0, España, pp. 19-45.

Edwards, Alberto. 1997. La fronda aristocrática en Chile, Santiago, Editorial Universitaria.

Estado Mayor General del Ejército de Chile. 1981. Héroes y soldados ilustres del Ejército de Chile, Santiago.

Estado Mayor General del Ejército. 1980. Historia del Ejército de Chile, vol. III, Santiago.

Figueroa, Pedro. 1897. Diccionario biográfico de Chile, vol. I, Santiago, Imprenta y Encuadernación Barcelona.

Figueroa, Virgilio. 1925. Diccionario histórico y biográfico de Chile 1800-1825, vol. II, Santiago, Imprenta y Litografía La llustración.

Finer, Samuel E. 1969. Los militares en la política mundial, Buenos Aires, Editorial Sudamericana.

Galdames, Luis. 1924. Historia política de Chile. La evolución constitucional, Santiago, Editorial Balcells.

González S., Edmundo. 1963. Soldados ilustres del Ejército de Chile, Santiago, Estado Mayor del Ejército.

Heise, Julio. 1974. Historia de Chile. El periodo parlamentario. 1861-1925, vol. I. fundamentos históricoculturales del parlamentarismo chileno, Santiago, Editorial Andrés Bello.

Heise, Julio. 1978. Años de formación y aprendizaje políticos 1810-1833, Santiago, Editorial Universitaria.

Infante, Javier. 2014. Autonomía, Independencia y República en Chile 1810-1828, Santiago, Centro de Estudios Bicentenario.

Pasquino, Gianfranco. 1991. “Militarismo”, en Bobbio, Norberto, Matteucci, Nicola y Pasquino, Gianfranco (directores), Diccionario de Política, Madrid, Alianza Editorial, pp. 962-970.

Pinto Vallejos, Julio, y Verónica Valdivia Ortiz de Zarate. 2009. ¿Chilenos todos? La construcción social de la nación (1810-1840), Santiago, LOM Ediciones.

Rojas, Gonzalo. 1989. "Portales y la seguridad interior del Estado", en Bravo Lira, Bernardino (comp.), Portales. El hombre y su obra la consolidación del gobierno civil, Santiago, Editorial Jurídica de Chile Editorial Andrés Bello, pp. 55-86.

Salazar, Gabriel. 2011 (2006). Construcción de Estado en Chile (1800-1837). Democracia de los "pueblos". Militarismo ciudadano. Golpismo oligárquico, Santiago, Editorial Sudamericana. 
San Francisco, Alejandro. 2010. La Guerra Civil de 1891. La irrupción política de los militares en Chile, vol. 1, Santiago, Centro de Estudios Bicentenario.

San Francisco, Alejandro. 2020. "El Ejército y la definición de sus principios constitucionales. Obediencia y no deliberación política en Chile. 1829-1830”, en Historia Caribe, vol. 15, №36, Colombia, pp. 235277.

Silva Castro, Raúl. 1958. Prensa y periodismo en Chile (1812-1956), Santiago, Ediciones de la Universidad de Chile.

Vergara Quiroz, Sergio. 1993. Historia social del Ejército de Chile, volumen I, Santiago, Departamento Técnico de Investigación - Universidad de Chile.

Verbal, Valentina. 2020. "De hermana mayor a madre protectora. Santiago frente a las provincias (18101860)", en Cartes, Armando (ed.), Región y Nación. La construcción provincial de Chile. Siglo XIX, Santiago, Editorial Universitaria, 2020, pp. 187-217. 